\title{
The antidepressant-like effects of pioglitazone in a chronic mild stress mouse model are associated with PPARY-mediated alteration of microglial activation phenotypes
}

Qiuying Zhao', Xiaohui Wu' ${ }^{1}$, Shuo Yan ${ }^{1}$, Xiaofang Xie ${ }^{2}$, Yonghua Fan' ${ }^{1}$, Jinqiang Zhang ${ }^{1}$, Cheng Peng ${ }^{2 *}$ and Zili You ${ }^{1 *}$

\begin{abstract}
Background: Discoveries that microglia-mediated neuroinflammation is involved in the pathological process of depression provided a new strategy for novel antidepressant therapy. Peroxisome proliferator-activated receptor $\gamma$ (PPARY) is a nuclear receptor regulating inflammation and microglial polarization and, therefore, a potential target for resolving depressive disorders. Our hypothesis was that antidepressant effects could be achieved through antiinflammatory and neuroprotective activities by PPARY-dependent microglia-modulating agents.

Methods: Chronic mild stress (CMS) treatment was performed on C57BL/ 6 mice for 6 weeks. After 3 weeks with the CMS procedure, depressive-like behaviors were evaluated by sucrose preference (SP), tail suspension test (TST), forced swimming test (FST), and locomotor activity. Pioglitazone was administered intragastrically once per day for 3 weeks at different doses. Neuroinflammatory cytokines were determined by real time-PCR (RT-PCR), enzyme-linked immunosorbent assay (ELISA), and western blot. The activated microglial state was confirmed by immunohistochemistry. N9 microglial cells were subjected to lipopolysaccharide, pioglitazone, and GW9662 to discuss the phenotype of activated microglia by RT-PCR, ELISA, and western blot.

Results: It was demonstrated that the PPARY agonist pioglitazone $(2.5 \mathrm{mg} / \mathrm{kg})$ ameliorated depression-like behaviors in CMS-treated mice, as indicated by body weight (BW), the SP test, the FST, and the TST. The amelioration of the depression was blocked by the PPARY antagonist GW9662. The expression of M1 markers (IL-1 $\beta$, IL-6, TNFa, iNOS, and CCL2) increased, and the gene expression of M2 markers (Ym1, Arg1, IL-4, IL-10, and TGF $\beta$ ) decreased in the hippocampus of the stresstreated mice. Pioglitazone significantly inhibited the increased numbers and morphological alterations of microglia in the hippocampus, reduced the elevated expression of microglial M1 markers, and increased the downgraded expression of microglial M2 markers in C57BL/6 mice exposed to CMS. In an in vitro experiment, pioglitazone reversed the imbalance of $\mathrm{M} 1$ and $\mathrm{M} 2$ inflammatory cytokines, which is correlated with the inhibition of nuclear factor kB activation and is expressed in LPS-stimulated N9 microglial cells.

(Continued on next page)
\end{abstract}

\footnotetext{
*Correspondence: pengchengchengdu@126.com; youzili@uestc.edu.cn

${ }^{2}$ State Key Laboratory Breeding Base of Systematic Research, Development and Utilization of Chinese Medicine Resources, Pharmacy College, Chengdu University of Traditional Chinese Medicine, Chengdu 6111376, China

${ }^{1}$ School of Life Science and Technology, Center for Informational Biology,

University of Electronic Science and Technology of China, Chengdu 610054, China
} 
(Continued from previous page)

Conclusions: We showed that pioglitazone administration induce the neuroprotective phenotype of microglia and ameliorate depression-like behaviors in CMS-treated C57BL/6 mice. These data suggested that the microgliamodulating agent pioglitazone present a beneficial choice for depression.

Keywords: Pioglitazone, PPARY, Antidepressant, CMS, Microglia, Alternative activation, Cytokine

\section{Background}

Major depressive disorder (MDD) is one of the most frequently occurring mental disorders and has a considerable rate of mortality [1]. The medications currently available to treat depression, including monoamine oxidase inhibitors (MAOIs), selective serotonin reuptake inhibitors (SSRIs), and tricyclic antidepressants, are predicated on the monoamine hypothesis. Clinical evidence shows that these medications produce adequate remission of depressive symptoms in only two thirds of patients [2]. Moreover, monoamine antidepressants such as SSRIs or MAOIs often have a slow onset of action and serious side effects [3]. Increasing evidence indicates that depression is accompanied by inflammatory responses $[4,5]$. A recent study reported that the imbalance of pro- and anti-inflammatory cytokines plays a critical role in chronic mild stress (CMS)-induced depression [6]. Research into the role of neuroinflammatory responses has brought new insights into the potential etiologies of MDD and provided new strategies for novel antidepressant therapies.

Microglia are resident innate immune cells within the central nervous system (CNS) and play a central role in the neuroinflammatory response. Microglia populate the CNS during early fetal life and are present in a resting state in the healthy brain but readily become activated in response to brain trauma, injury, and infection $[7,8]$. In clinical research, microglial activation has also been observed in patients with depression who have committed suicide [9]. Microglial activation is often categorized into classical (M1) and alternative (M2). M1 microglia may contribute to dysfunction of the neurotrophic system by expressing pro-inflammatory cytokines, such as tumor necrosis factor- $\alpha$ (TNF $\alpha)$, IL-1 $\beta$, IL- 6 , iNOS, and CCL2 [10]. In the M1 phenotype of microglia, the activation of nuclear factor $\mathrm{kB}(\mathrm{NF}-\mathrm{kB})$ may play a critical role in the production of proinflammatory cytokines, leading to neurotoxic outcomes [11]. The M2 phenotype, sometimes called the neuroprotective microglial phenotype, releases different mediators including $\mathrm{Ym} 1$, arignase1 (Arg1), IL-4, IL-10, and TGF $\beta$ [10] to antagonize inflammation-induced damage in the CNS [12, 13]. Stress triggers neuroinflammatory processes in several brain regions including the frontal cortex, hypothalamus, and hippocampus $[14,15]$. More specifically, the hippocampus is an area particularly sensitive to chronic stress, which was associated with evidence of inflammation characterized by microglial activation [16]. In this study, the hippocampus was chosen for investigation because of the effects of hippocampal microglial activation on stress-induced behaviors.

Pioglitazone is a highly selective agonist for PPAR $\gamma$, which causes the transcription of several genes involved in glucose and lipid metabolism as well as with the production of inflammatory mediators [17, 18]. In recent years, researchers have found that PPAR $\gamma$ agonists might be useful in a number of central nervous system diseases that have a microglia-induced anti-inflammatory response $[19,20]$. Pioglitazone is primarily used as an antidiabetic drug [21] and recently has been used in clinical trials for psychiatric and neurodegenerative diseases. It has been reported that pioglitazone promotes cognitive and functional improvements in schizophrenia and autism [22]. Pioglitazone is also being tested in Alzheimer's disease [23], Parkinson's disease [24], multiple sclerosis [25], and stroke [26]. In clinical trials, pioglitazone worked as an adjuvant treatment for depression in insulin-resistant subjects and was associated with improvement in glucose metabolism [27]. Researchers have also reported that pioglitazone had antidepressant-like effects in an acute animal model of depression, although the mechanisms underlying their beneficial effect remain largely unknown $[28,29]$. Accumulating evidence indicates that inhibition of the microglia-mediated inflammatory response is an important strategy for the treatment of mood disease [30].

Based on the effects of PPAR $\gamma$ on the anti-inflammatory response, in this study we evaluated the antidepressantlike effects of the PPARY agonist pioglitazone in CMSinduced depression using a mouse model and analyzed the role of M2 microglia in the antidepressant activity of pioglitazone.

\section{Methods \\ Animals}

Male C57BL/6 mice weighing 18-22 g were purchased from the Institute of Experimental Animals (Chengdu, China). The animals were housed individually under controlled conditions $\left(23-25{ }^{\circ} \mathrm{C}\right.$, humidity $50-60 \%$, on a 12-h light/dark cycle with lights on at 8:00 a.m. and water and food available ad libitum) and acclimatized for at least 1 week before they were used for the experiments. All the 
behavioral experiments were conducted in isolated behavioral testing rooms and performed by an experimenter who was blind to the identity of the experimental groups.

\section{CMS procedure}

The CMS procedure was performed according to previously described methods, but with small modifications $[31,32]$. The stress method followed a random schedule of commonly used mild stressors, such as food deprivation for $24 \mathrm{~h}$, water deprivation for $24 \mathrm{~h}$, cage tilting $\left(45^{\circ}\right)$ for $24 \mathrm{~h}$, damp bedding for $24 \mathrm{~h}$, stroboscopic illumination for $24 \mathrm{~h}$, overnight illumination, and restraint stress for $2 \mathrm{~h}$. The mice received one stressor once per day with the same stressor never applied in two consecutive days. The stress regimen lasted for six consecutive weeks. The control group was housed in a separate room and had no contact with the stressed animals. After the 3 weeks with the CMS procedure, the stress-treated mice were divided into a vehicle group and drug-treatment groups. The body weight (BW) and sucrose preference (SP) data during the first 3 weeks while the mice were being stressed showed no statistical differences between the mice. The additional files showed this in more details (see Additional file 1 and Additional file 2).

\section{Drug treatment}

Depressive-like behaviors appeared after the 3 weeks of CMS induction. At the end of the 3-week induction period, the drugs and vehicle were administered intragastrically once per day for an additional 3 weeks. In order to determine the optimal dosage, for experiment 1 , the mice were allocated into six experimental groups according to treatment: Control (control group not submitted to CMS, $n=26$ ), CMS + Vehicle (CMS group without pioglitazone, $n=26$ ), CMS $+2.5 \mathrm{mg} / \mathrm{kg}$ (CMS animals and administered with pioglitazone at $2.5 \mathrm{mg} /$ $\mathrm{kg}, n=26)$, CMS $+5 \mathrm{mg} / \mathrm{kg}$ (CMS animals and administered with pioglitazone at $5 \mathrm{mg} / \mathrm{kg}, n=26), \mathrm{CMS}+$ $10 \mathrm{mg} / \mathrm{kg}$ (CMS animals and administered with pioglitazone at $10 \mathrm{mg} / \mathrm{kg}, n=26), \mathrm{CMS}+20 \mathrm{mg} / \mathrm{kg}$ (CMS animals and administered with pioglitazone at $20 \mathrm{mg} / \mathrm{kg}, n=26$ ). In experiment $1, \mathrm{BW}$ and SP test were evaluated in the same group $(n=10)$. The tail suspension test (TST) and locomotor activity were assessed in the same animals $(n=8)$. The forced swimming test (FST) was estimated in the six groups $(n=8)$. In all the experiments, the vehicle was $10 \%$ dimethyl sulfoxide diluted with $0.9 \%$ saline.

In order to investigate the possible involvement of a PPAR $\gamma$ pathway, for experiment 2, the mice were allocated into five experimental groups according to treatment: control (control group not submitted to CMS, $n=26$ ), CMS + Vehicle (CMS group and $0.9 \%$ saline, $n=26)$, CMS + Piog (CMS animals and administered with pioglitazone at $2.5 \mathrm{mg} / \mathrm{kg}, n=26), \mathrm{CMS}+$ GW (CMS animals and administered with GW, the mice were pretreated for $1 \mathrm{~h}$ with $1 \mathrm{mg} / \mathrm{kg}$ of GW, a specific PPAR $\gamma$ inhibitor, before pioglitazone administration, $n=26), C M S+P i o g+G W \quad(C M S$ animals and administered with pioglitazone at $2.5 \mathrm{mg} / \mathrm{kg}$ and $\mathrm{GW}$ at $1 \mathrm{mg} / \mathrm{kg}, n=26$ ). In experiment 2 , BW and SP test were evaluated in the same animals $(n=10)$. The TST and locomotor activity were assessed in the same mice $(n=8)$. The FST was estimated in the five group of animals $(n=8)$. The immunofluorescence experiment was performed for microglial phenotype in the control $(n=5)$, CMS + Vehicle $(n=5)$, CMS + Piog $(n=5), \mathrm{CMS}+\mathrm{GW}$ $(n=5)$, and CMS + Piog + GW $(n=5)$ animals. The relative expression of the M1 and M2 markers was quantified by real time-PCR (RT-PCR) in all of the five groups ( $n=5$ for each group). The pioglitazone (Sigma, USA) and GW9662 (Sigma, USA) were all diluted with $10 \%$ dimethyl sulfoxide (Sigma, USA) in $0.9 \%$ saline. Thirty minutes after the last drug administration, the mice were used in the behavioral tests as well as in cellular and molecular experiments.

\section{Body weight measurement and sucrose preference test}

As the primary assessment indicators for $\mathrm{BW}$ and anhedonia in an animal model of depression, BW and SP were measured at the onset of the CMS schedule and every week until the end of the 6-week CMS test. BW was measured once a week at 5:00 p.m. on Mondays to calculate the BW gain during the CMS period. The BW test and the SP test were administered to all the mice in all the groups.

Before the SP test, individually housed mice were habituated to consume $1 \%$ sucrose solution. The test involved $20 \mathrm{~h}$ of food and water deprivation, followed by $1 \%$ sucrose and water intake for $2 \mathrm{~h}$. The position of the two bottles (left/right sides of the cages) was varied randomly in each trial. The intake of sucrose solution and water was recorded every week at 5:00 p.m. on Tuesdays for 6 weeks throughout the CMS experiment to evaluate the anhedonia of the mice. The SP was calculated according to the ratio: $\mathrm{SP}=$ sucrose intake $(\mathrm{g}) /$ [sucrose intake $(\mathrm{g})+$ water intake $(\mathrm{g})]$.

\section{Locomotor activity measurement}

To measure the locomotor activities of the mice, we used a 36-point infrared ray passive sensor system (model No. ZZ-6, Taimeng Tech Ltd. Chengdu, China) in the sixth week of the experimental procedure, that is, at the end of the test. Each of the mice was placed in a chamber of an autonomous movement device to accommodate to the environment for $1 \mathrm{~min}$ before the test. The total locomotor activity (standing and movement) 
of the mice was automatically recorded by the autonomous movement equipment for $10 \mathrm{~min}$.

\section{Tail suspension test}

The TST is based on the fact that mice subjected to the short-term, inescapable stress of being suspended by their tail will develop an immobile posture [33]. In this test, which was also done once to all mice in the sixth week of the experiment, adhesive tape (approximately $1 \mathrm{~cm}$ from the tip of each mouse's tail) was used to suspend the mice by the tail from a ledge $20 \mathrm{~cm}$ above a tabletop. Each animal was isolated to avoid interference during the experiment. The mice were recorded by a video camera. Immobility was defined as the absence of movement for 6 min and was used as an evidence of hopelessness.

\section{Forced swimming test}

The FST models depressant-like behavior as decreased immobility. We used the method described by Porsolt [34] with a slight modification. The mice were placed in an open glass cylindrical container $(20 \mathrm{~cm}$ in height and $14 \mathrm{~cm}$ in diameter) with 10 -cm-deep water $\left(25 \pm 1{ }^{\circ} \mathrm{C}\right)$ for $6 \mathrm{~min}$. Immobility time was recorded as the amount of time the mice floated passively without struggling in the water. This test was also done once to all mice in the sixth week of the experiment. The duration of immobility in the last $4 \mathrm{~min}$ of the total $6 \mathrm{~min}$ was recorded as evidence of despair.

\section{Immunofluorescence}

The animals were anesthetized with pentobarbital sodium, perfused transcardially with $\mathrm{pH} 7.2$ phosphatebuffered saline (PBS) and $4 \%$ paraformaldehyde. Coronal sections were cut into $35-\mu \mathrm{m}$ slices with a sliding vibratome (CM1900; Leica Microsystems, Wetzlar, Germany). The immunofluorescence and statistical methods were based on our previously described methods [35]. The brain sections that contained the hippocampus and N9 microglial cells were permeabilized with $0.5 \%$ Triton X-100 for $10 \mathrm{~min}$. The samples were placed in $10 \%$ donkey serum for $2 \mathrm{~h}$; incubated with a primary antibody, goat anti-ionized calcium-binding adaptor protein-1 (Iba1) (1:600; Abcam), overnight at $4{ }^{\circ} \mathrm{C}$; and then incubated with a fluorescent-dye-conjugated secondary antibody, DyLight 549-conjugate donkey anti-goat (1:500; Jackson ImmunoResearch). Positive cells were manually counted under a $\times 40$ objective microscope (Olympus BX51). The photomicrographs were saved as TIF files and quantitatively analyzed using the cell counter in the ImageJ software (version 1.45J; National Institutes of Health, Bethesda, MD, USA).

\section{Cell culture}

Murine N9 microglial cells (kindly provided by Dr. H. Han, Institute of Neuroscience, Fourth Military Medical University, China) were cultured in DMEM (Invitrogen, USA) with the addition of $10 \%$ fetal bovine serum (Invitrogen, USA), $100 \mathrm{U} / \mathrm{ml}$ penicillin (Invitrogen, USA), and $0.1 \mathrm{mg} / \mathrm{ml}$ streptomycin (Invitrogen, USA) in a humidified atmosphere of $5 \% \mathrm{CO}_{2}$ and $95 \%$ air at $37{ }^{\circ} \mathrm{C}$. The cells were passaged two to three times per week and then distributed into 24-well plates at a density of $5 \times 10^{5}$ cells per well. The cultivated N9 cells were treated with or without lipopolysaccharide (LPS) (for simulating an organism's inflammatory environment in vitro), pioglitazone, and GW9662. The concentrations were as follows: LPS (Sigma, USA): $100 \mathrm{ng} / \mathrm{ml}$; pioglitazone (Sigma, USA): $10 \mu \mathrm{mol}$, and GW9662 (Sigma, USA): $1 \mu \mathrm{mol}$. After culturing for $24 \mathrm{~h}$, the cells were used in RT-PCR, ELISA, and western blot detection.

\section{ELISA}

The N9 cells were treated with RIPA Lysis Buffer (Beyotime Institute of Biotechnology, China) and centrifuged at $12,000 \mathrm{rpm}$ for $5 \mathrm{~min}$. The supernatants were collected to detect the protein levels by ELISA and western blot. The expression of IL-1 $\beta$ and TNF $\alpha$ was assayed using ELISA kits (NeoBioscience Technology Co., Ltd., China) according to the manufacturer's protocol. The detection limits for IL-1 $\beta$ and TNF $\alpha$ were $1 \mathrm{pg} / \mathrm{ml}$. The absorbance at $450 \mathrm{~nm}$ was recorded using a microplate reader.

\section{Western blot analysis}

The protein concentrations were determined with a BCA kit (Beyotime Institute of Biotechnology, China) following the manufacturer's guidelines. Equal amounts of protein were separated by SDS-polyacrylamide gel electrophoresis, transferred to polyvinylidene difluoride membranes (Millipore, USA), and blocked with $5 \%$ skim milk incubated with primary antibody either overnight at $4{ }^{\circ} \mathrm{C}$ or for $1 \mathrm{~h}$ at room temperature. The membranes were washed and incubated with anti-rabbit IgG horseradish peroxidase-conjugated secondary antibody (1:500; Beyotime Institute of Biotechnology, China) using ECLPlus kits (Millipore, USA) as a detection system. Densitometry was performed to quantify the signal intensity using ImageJ software (Version $1.45 \mathrm{~J}$; National Institutes of Health, Bethesda, MD, USA). The primary antibodies were rabbit anti-Ym1 (1:800; Abcam, USA), rabbit antiArg1 (1:800; Abcam, USA), and rabbit anti-IkB $\alpha$ (1:1000; Cell Signaling Technology, USA).

\section{Real-time PCR}

The mice were sacrificed by decapitation, and the hippocampus was quickly dissected out and placed in sterile 
tubes. The total RNA of the hippocampus and the N9 cells were harvested using Trizol reagent (Invitrogen, USA) according to the manufacturer's instructions. The first strand complementary DNA (cDNA) was synthesized with a cDNA Synthesis Kit (TAKARA, Japan). The PCR amplifications were conducted in a $10-\mu$ l reaction volume. RT-PCR was carried out in a Bio-Rad CFX 96 at $95{ }^{\circ} \mathrm{C}$ for $10 \mathrm{~min}$ followed by 38 cycles of $95^{\circ} \mathrm{C}$ for $3 \mathrm{~s}$, $60{ }^{\circ} \mathrm{C}$ for $30 \mathrm{~s}$, and $72{ }^{\circ} \mathrm{C}$ for $5 \mathrm{~s}$. The relative gene expression was calculated using the Ct method, as in our previous study [12]; the loading control was $\beta$-actin. Primer sequences were as follows: IL-1 $\beta, 5^{\prime}$-CCAGC AGGTTATCATCATCATCC-3', 5' -CTCGCAGCAGCA CATCAAC-3', [GenBank: NM_008361.4]; IL-6, 5'AGAGATACAAAGAAATGATGGA-3', 5' -AGCTATG GTACTCCACAAGACCA-3', [GenBank: NM_03116

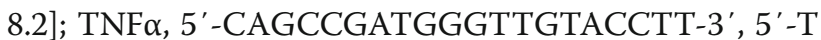
GTGGGTGAGGAGCACGTAGT-3', [GenBank: NM_01 3693.3]; iNOS, 5'-GCAGAGATTGGAGGCCTTGTG3', 5'-GGGTTGTTGCTGAACTTCCAGTC-3', [GenBank: NM_010927.4]; CCL-2, 5'-CTGATGCAGGTC CCTATGGT-3', 5' -GCAGGATTTTGAGGTCCAGA3', [GenBank: NM_009137.2]; Ym1, 5'-TCACTTACAC ACATGAGCAAGAC-3', 5'-CGGTTCTGAGGAGTAG AGACCA-3', [GenBank: NM_009892.3]; Arg1, 5'-GG AAGACAGCAGAGGAGGTG-3', 5 '-TATGGTTACCC TCCCGTTGA-3', [GenBank: NM_007482.3]; IL-4, 5' CAGCTAGTTGTCATCCTGCTCTTC-3', 5' -GCCGAT GATCTCTCTCAAGTGA-3', [GenBank: NM_02128 3.2]; IL-10, 5'-GGCAGAGAACCATGGCCCAGAA-3', 5'-AATCGATGACAGCGCCTCAGCC-3', [GenBank: N M_010548.2]; TGF $\beta$, 5'-GACCGCAACAACGCCATCT A-3', 5' -GGCGTATCAGTGGGGGTCAG-3', [GenBank: NM_011577.2]; $\beta$-actin, 5'-CCGTGAAAAGATG ACCCAGATC-3', 5' -CACAGCCTGGATGGCTACGT3', [GenBank: NM_007393.5].

\section{Statistical analysis}

The data were expressed as means \pm SEM. The results of the BW and SP test were analyzed with a two-way analysis of variance (ANOVA). The other statistical significances were assessed by one-way ANOVAs followed by Bonferroni's multiple comparison test using Windows ${ }^{\circ}$ v.17 (SPSS Inc., Chicago, USA). A value of $p<0.05$ was considered statistically significant.

\section{Results}

\section{The effects of different doses of pioglitazone on CMS-} treated mice

The experimental design is presented in Fig. 1a. There were no differences in the BW or SP between the six groups at the baseline measurement (week 0: $p>0.05$, respectively). The BW of the CMS mice slowly increased compared with that of the control group throughout the
3 weeks of the CMS procedure. After 3 weeks of continuous treatment with pioglitazone for the CMS mice, the doses of 2.5 and $5.0 \mathrm{mg} / \mathrm{kg}$ pioglitazone had restored the CMS-induced BW reduction in the mice to a level comparable to that of the CMS + Vehicle group $(p<0.01$ and $p<0.05$, respectively; Fig. $1 \mathrm{~b}, \mathrm{c})$. A reduction in the relative sucrose intake (anhedonia) was observed in the mice after the 3-week period of CMS. The anhedonia improved following the 2.5 and $5.0 \mathrm{mg} / \mathrm{kg}$ dosages to a level that was comparable to that of the CMS + Vehicle mice $(p<0.01$, both; Fig. 1d, e). Additional file 1 provides the 6 -week details of BW and SP in experiment 1 .

With 6 weeks of CMS induction, the immobility time increased in the CMS + Vehicle mice. Three weeks of treatment with pioglitazone at $2.5,5.0$, and $10 \mathrm{mg} / \mathrm{kg}$ significantly reduced the duration of immobility compared to the untreated CMS group ( $p<0.01$; Fig. 1f).

In the TST, after 6 weeks of CMS induction, the duration of the immobility increased in the CMS group compared with the control group. The immobility time of the pioglitazone $(2.5$ and $5.0 \mathrm{mg} / \mathrm{kg})$-treated mice was shorter than that of the CMS + Vehicle mice $(p<0.05$; Fig. 1g).

As shown in Fig. 1h, the CMS + Vehicle group showed decreased spontaneous movement times compared with the control animals $(p<0.05$; Fig. $1 \mathrm{~h})$. The spontaneous activity levels increased in the $2.5,5.0$, and $10 \mathrm{mg} / \mathrm{kg}$ pioglitazone groups compared with the stressed, but untreated, mice. According to the depression indicators above, the antidepressant effect was greatest at the $2.5 \mathrm{mg} / \mathrm{kg}$ pioglitazone level.

\section{The effects of pioglitazone on behaviors of CMS-treated mice blocked by GW9662}

As shown in Fig. 2a, GW9662 was chosen to inhibit the PPAR $\gamma$ activity. The BW and SP baselines did not differ between the five groups $(p>0.05$, both; Fig. $2 \mathrm{~b}, \mathrm{~d})$, but the CMS induction reduced the BW and SP in week 6 compared with the control group. After 3 weeks of drug administration, pioglitazone reversed the body loss and increased the sucrose intake compared with the CMS + Vehicle mice. GW9662 aggravated the weight loss and anhedonia after the CMS procedure $(p<0.01, p<0.05$; Fig. 2c, e). Mice treated with pioglitazone and GW9662 in the CMS groups also decreased in BW, but not SP, compared to the CMS + Vehicle group. Only the week 6 data for the BW and SP tests are shown in Fig. 2. Additional file 2 shows more details for the BW and SP.

The mice exposed to CMS induction showed reduced locomotor movement during the 6 weeks of stress treatment compared with the control animals. Pioglitazone increased the durations of their spontaneous movement after 3 weeks of administration, whereas GW9662 treatment decreased the spontaneous activity level compared 


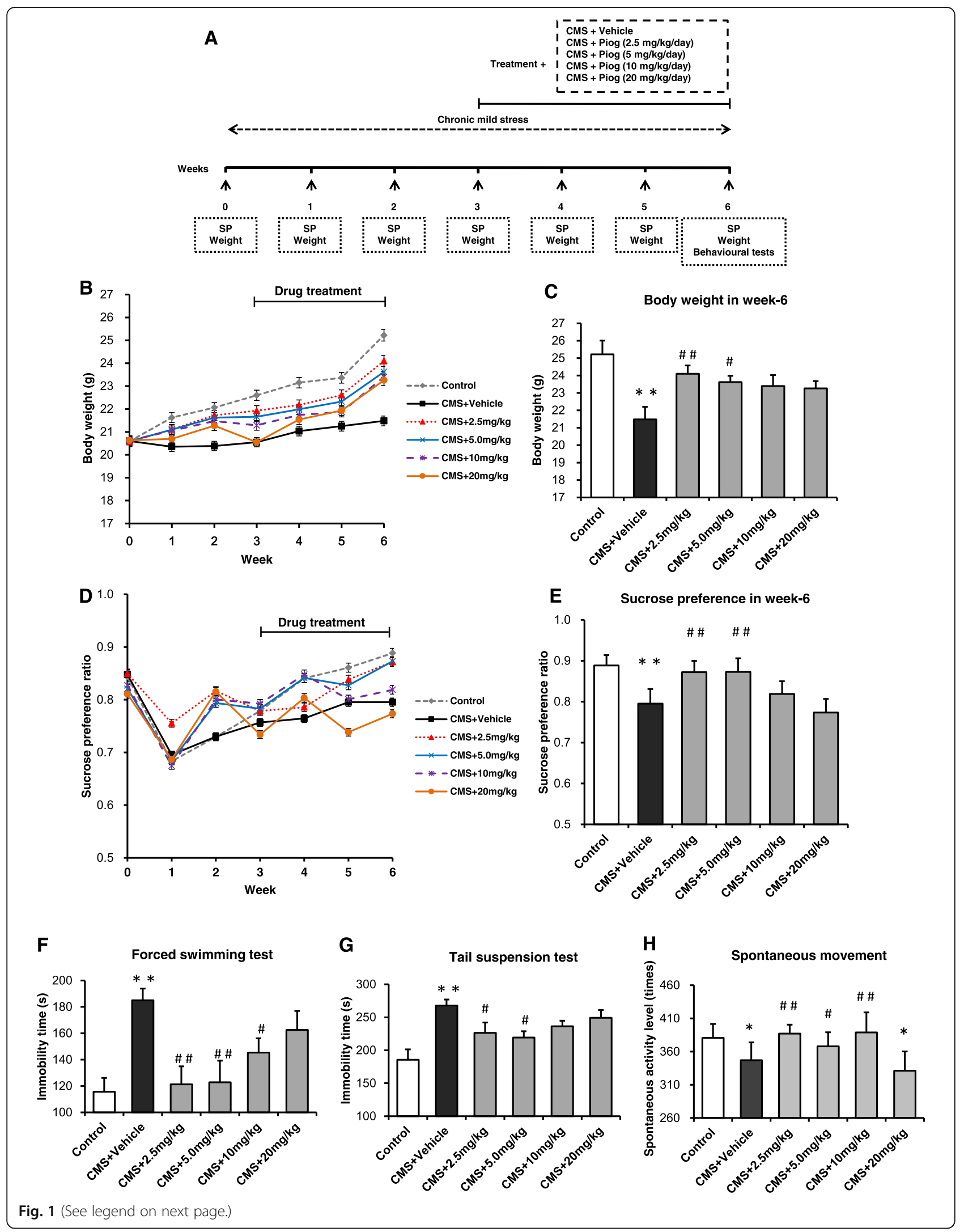


(See figure on previous page.)

Fig. 1 Effects of pioglitazone at different doses on CMS mice. a Schematic diagram of the experimental design. BW was measured every week (b). The $2.5 \mathrm{mg} / \mathrm{kg}$ dose showed the best result in recovering the BW in the CMS mice $(\mathbf{c}, n=10)$. Anhedonia was detected by SP over the course of the 6-week-long experiment (d, e, $n=10$ ). The duration of immobility in the FST ( $\mathbf{f}$ ) and TST ( $\mathbf{g}$ ) increased after CMS induction at the sixth week ( $n=8$ in both tests). Pioglitazone $(2.5 \mathrm{mg} / \mathrm{kg}$ ) reduced this increase. In the locomotor activity test, pioglitazone improved the spontaneous activity level after CMS induction (h, $n=8) .{ }^{*} p<0.05,{ }^{*}{ }^{*} p<0.01$ vs. Control; ${ }^{*} p<0.05,{ }^{\# \#} p<0.01$ vs. CMS + Vehicle. Data are expressed as means \pm SEM

with the controls and the CMS + Piog $(p<0.05)$. Pioglitazone and GW9662 combined did not significantly change the effect of the CMS (Fig. 2f).

In the FST, the duration of the immobility increased in the CMS + Vehicle animals, whereas the time was restored to the control level with a 3-week pioglitazone treatment. After administration with the PPARY antagonist GW9662, the immobility time increased, compared to the control mice $(p<0.05$; Fig. $2 \mathrm{~g})$. There were no significant differences in the FST between the treatment of the CMS-exposed mice with the two-drug (pioglitazone and GW9662) combination and the control group.

Figure $2 \mathrm{~h}$ depicts the effect of PPAR $\gamma$ on depression improvement in the TST experiment. The immobility time of the CMS + Vehicle as well as of the CMS + GW9662 mice was longer than that of the control group. Mice that received pioglitazone either alone or in combination with GW9662 had a shorter immobility duration than the CMS + Vehicle mice $(p<0.05$; Fig. $2 \mathrm{~h})$.

\section{The activity of PPARY affects the microglial activated status}

After 6 weeks of CMS induction, the morphology of the $\mathrm{Iba}^{+}$microglia was amoeboid (Fig. 3a) and their numbers increased in the hippocampus of the CMS + Vehicle mice compared with the control animals (Fig. 3b). The number of $\mathrm{Iba1}^{+}$microglia in the mice which received the CMS induction was lower in the animals that received the PPAR $\gamma$ agonist, pioglitazone. The number of $\mathrm{Iba}^{+}$microglia increased and their amoeboid shape remained following the administration of the PPAR $\gamma$ antagonist GW9662. Pioglitazone and GW9662 treatment together did not change the number or morphology of the $\mathrm{Iba} 1^{+}$microglia compared with the CMS + Vehicle group $(p<0.01$; Fig. $3 \mathrm{~b})$.

We next studied the activated phenotype of the microglia in the hippocampus. The expression of M1 markers, IL-1 $\beta$, IL-6, TNF $\alpha$, iNOS, and CCL2, increased in the CMS + Vehicle mice. After treatment with pioglitazone, the expression of M1 markers decreased. Administration of pioglitazone and GW9662 did not change the activation status of the microglia in the CMS animals (Fig. 4a: $p=0.018$; Fig. 4b: $p=0.051$; Fig. 4c: $p=0.045$; Fig. 4d: $p=0.008$; Fig. 4e: $p=0.032$ ). In the M2 status, the messenger RNA (mRNA) expression (Ym1, Arg1, IL-4, IL-10, and TGF $\beta$ ) was lower following the 6-week
CMS procedure. The decreases were attenuated by administration with pioglitazone (Fig. 5a: $p=0.001$; Fig. 5b: $p=0.004$; Fig. 5c: $p=0.001$; Fig. $5 \mathrm{~d}: p=0.037$; Fig. 5e: $p=0.046)$.

\section{The effects of pioglitazone on LPS-stimulated $\mathrm{N} 9$ microglial phenotypes in vitro}

In order to confirm the effect of pioglitazone on the microglial phenotypes, we detected the microglial activation status by using LPS simulate an organism's inflammatory environment in an N9 microglial line. As shown in Fig. 6, the expression of the M1 phenotype (IL-1 $\beta$, IL6 , TNF $\alpha$, iNOS, and CCL2) increased significantly after the LPS treatment compared with the control, Con + Piog, and Con + GW microglial cells. Pioglitazone markedly blocked the upregulation of these markers in the LPS groups. Co-treatment with pioglitazone, GW9662, and LPS showed no difference in the LPS microglia (Fig. 6a: $p=0.025$; Fig. 6b: $p=0.023$; Fig. 6c: $p=0.001$; Fig. 6d: $p=0.001$; Fig. 6e: $p=0.036$ ). In contrast, the expression of the M2 markers, Ym1, Arg1, IL-4, IL-10, and TGF $\beta$, decreased after LPS stimulation, but these expressions improved after treatment with pioglitazone. The microglial activated phenotypes of the LPS + Piog + GW group were similar to the LPS microglia (Fig. 7a: $p=0.010$; Fig. 7b: $p=0.012$; Fig. 7c: $p=0.025$; Fig. $7 \mathrm{~d}: p=0.040$; Fig. 7e: $p=0.032$ ). Consistent with these mRNA expressions, protein expression of the M1 pro-inflammatory cytokines (IL-1 $\beta$ and TNF $\alpha$ ) was also upregulated by LPS, and these effects were significantly inhibited by pioglitazone. There were no differences between the LPS and the LPS + Piog + GW cells (Fig. 6f: $p<0.001$; Fig. 6g: $p<0.001$ ). The protein levels of the M2 anti-inflammatory mediators ( $\mathrm{Ym} 1$ and Arg1) were also reduced with LPS treatment, and these decreases were attenuated by treatment with pioglitazone. There was no difference between the LPS and the LPS + Piog + GW microglia in their protein expression of either Ym1 or Arg1 (Fig. 7g: $p=0.041$; Fig. 7i: $p=0.026)$. The results for the $\mathrm{M} 1$ and $\mathrm{M} 2$ markers in the N9 microglia cells in vitro were consistent with the consequences in the mice in vivo.

Next, we investigated whether pioglitazone exerted its anti-inflammatory effects through regulating NF$\mathrm{kB}$ activity. Following the LPS treatment, the level of $\mathrm{IkB} \alpha$ in the N9 microglia dropped compared with all 


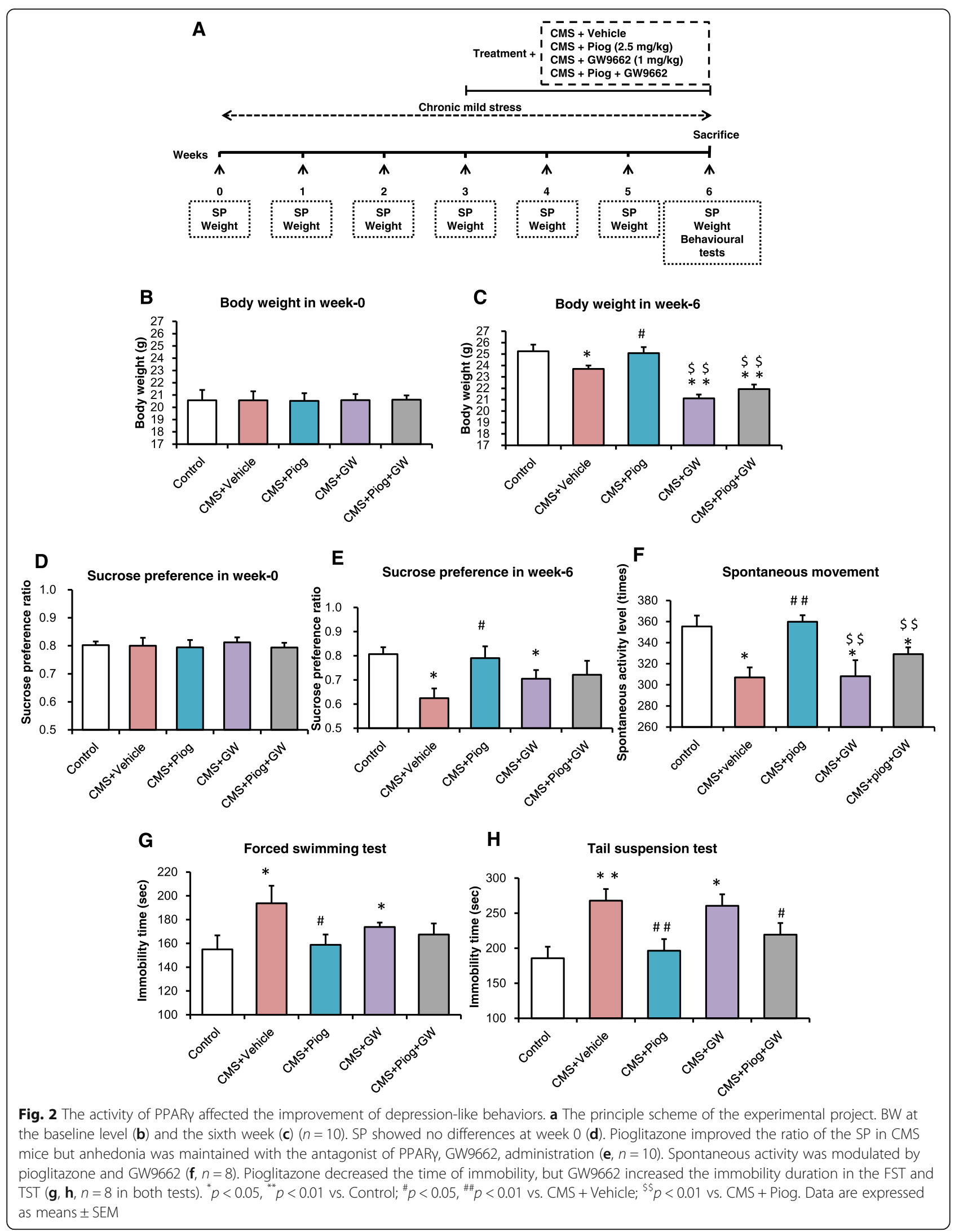



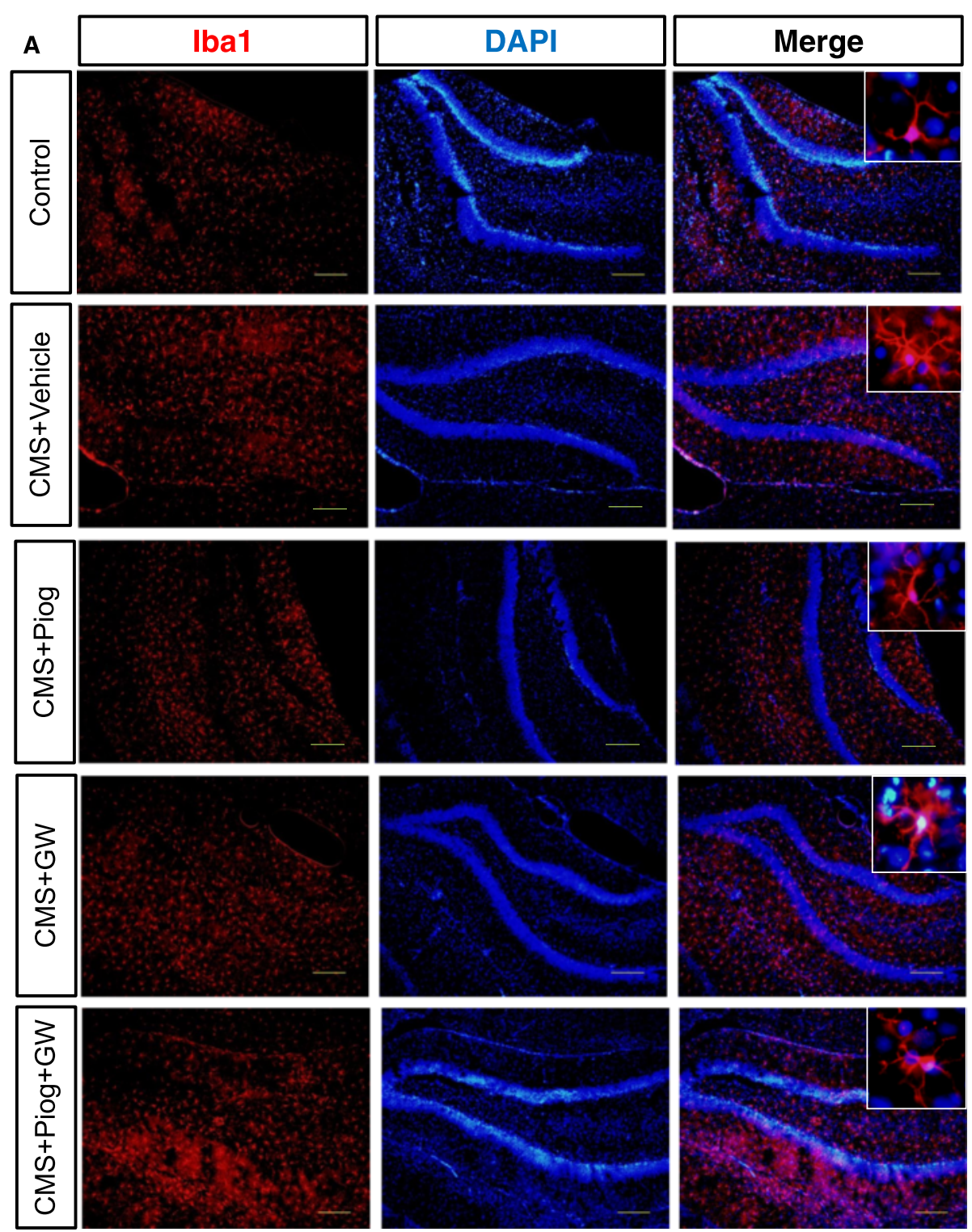

lba1

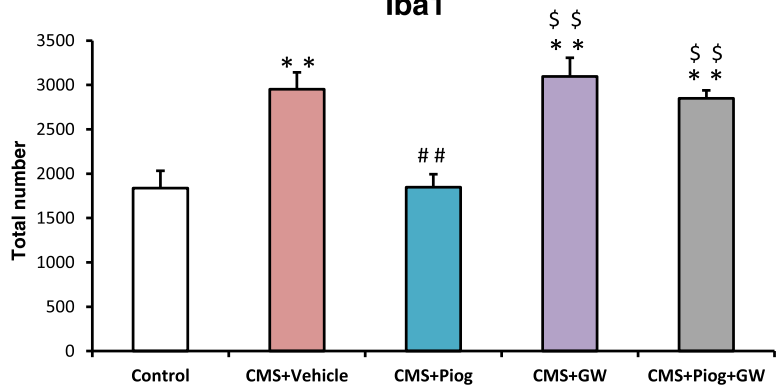

Fig. 3 Microglial activated status was influenced by PPARy in the hippocampus. Pioglitazone decreased the number of Iba $1^{+}$microglia compared with the CMS mice. The Iba1 ${ }^{+}$microglial morphology was amoeboid, and the number of microglia increased in the animals after GW9662 treatment. Administration of pioglitazone and GW9662 had no effect on the microglia $(\mathbf{b}, n=5)$. Enlarged figures indicate typical microglia (a). Scale bars: $10 \mu \mathrm{m}$. ${ }^{* *} p<0.01$ vs. Control; ${ }^{\# \#} p<0.01$ vs. CMS + Vehicle; ${ }^{\$ \$} p<0.01$ vs. CMS + Piog. Data are expressed as means \pm SEM 


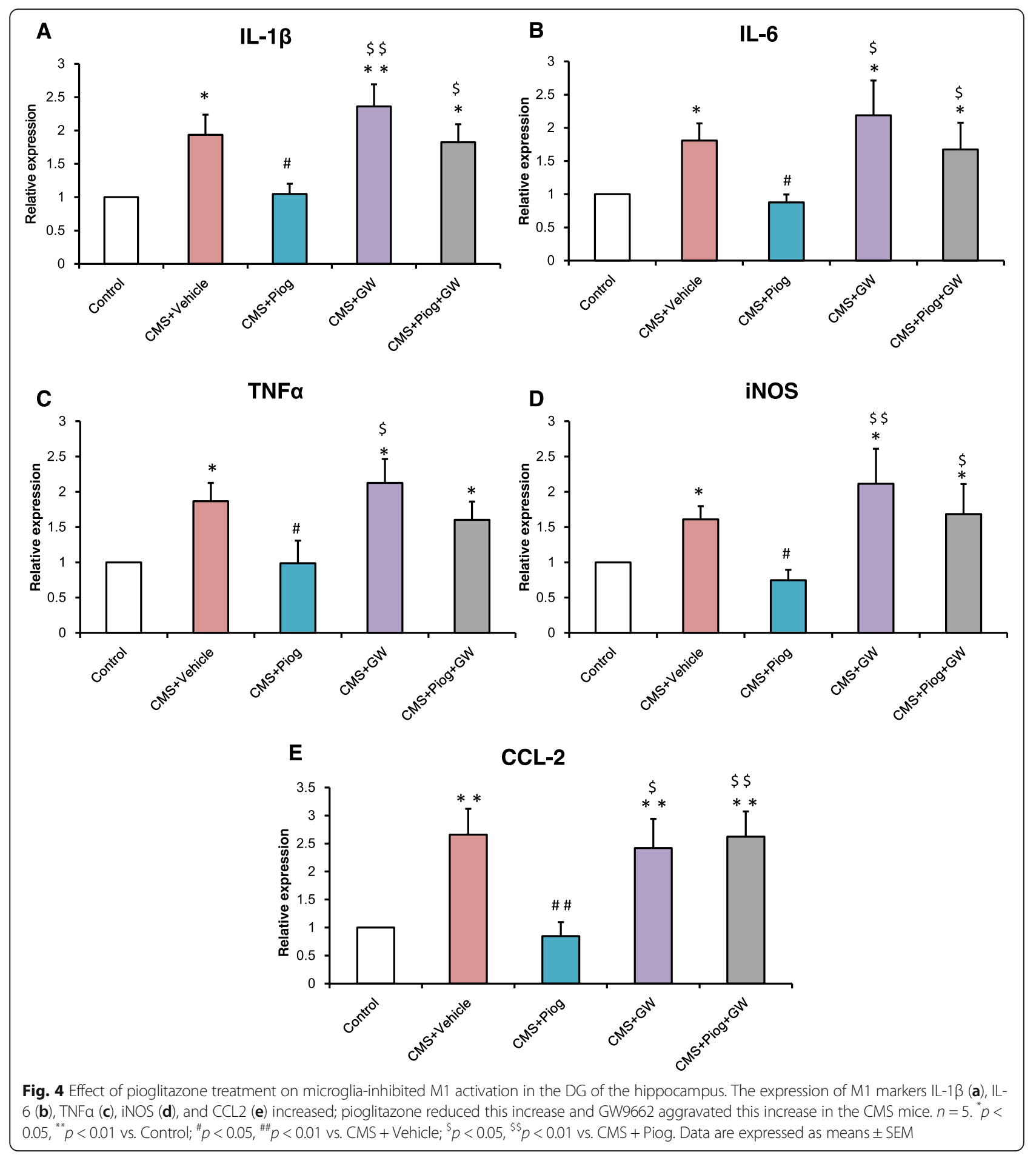

the control groups. Pioglitazone significantly increased the levels of $\mathrm{IkB} \alpha$ in the LPS-treated N9 cells, and GW9662 reversed this effect. Pioglitazone markedly upregulated the protein levels of $\mathrm{IkB \alpha}$, which repressed the inhibition of NF-kB activity (Fig. 7k: $p=0.026$ ).

\section{Discussion}

In this study, we investigated the antidepressant effect of pioglitazone and explored its underlying anti-inflammatory responses. First, pioglitazone ameliorated depression-like behaviors in CMS-treated mice, but this amelioration was diminished by GW9662. Second, pioglitazone exerted 


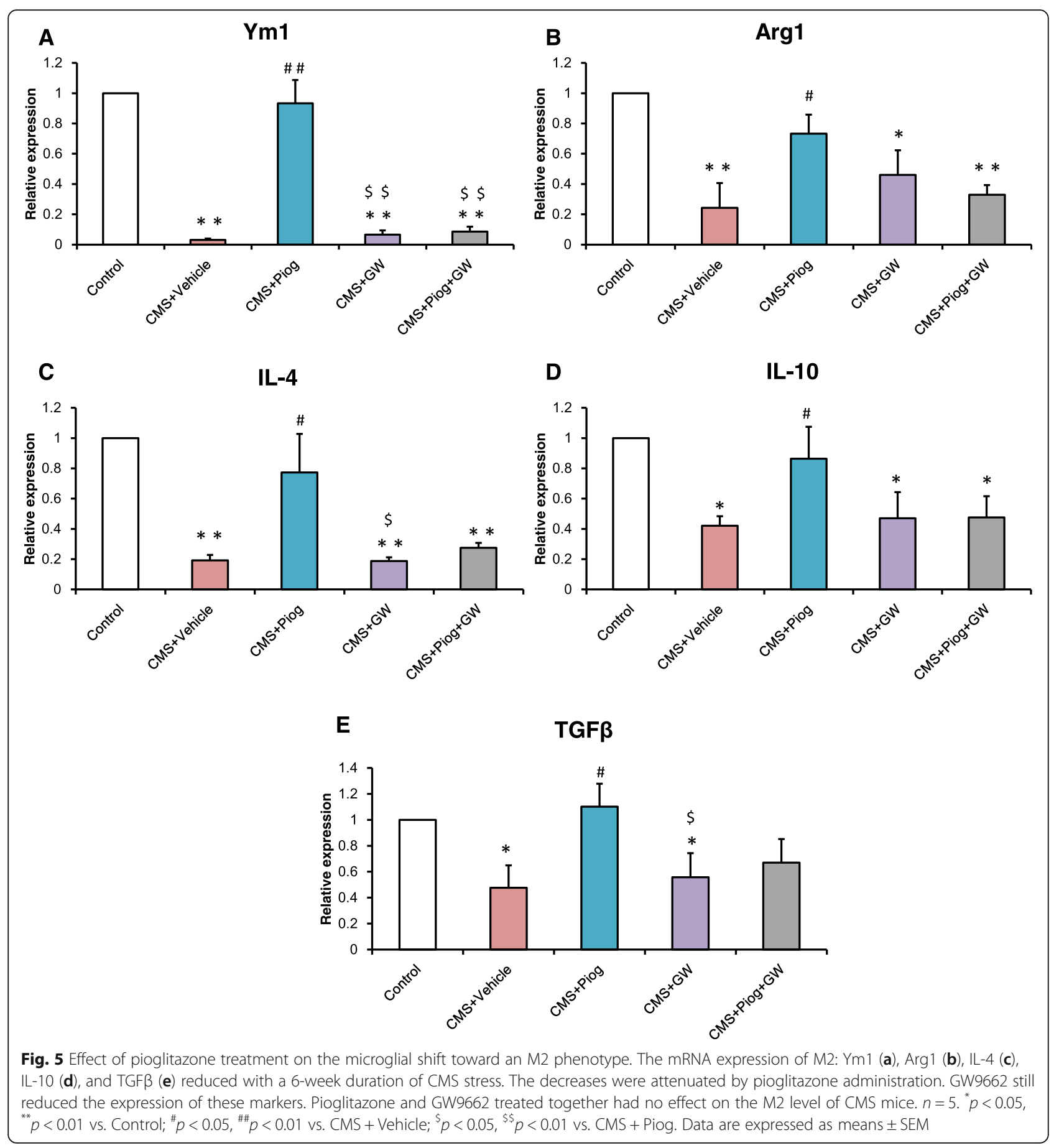

antidepressant effects through the anti-inflammatory activity of the PPAR $\gamma$ pathway. Third, pioglitazone improved CMS-induced depression-like behavior by regulating which of the microglial phenotypes (M1 or M2) was activated.

MDD is a common and sometimes fatal disorder that has increasingly become a public health concern. Accumulating evidence suggests that chronic low-grade inflammation plays an important role in the pathology of depression. Over the past two decades, great effort has been made to identify novel targets for antidepressant therapies. It has been proposed that pioglitazone, working as an anti-inflammatory agent, could produce antidepressant responses in patients with concomitant metabolic syndrome and diabetes [36, 37]. In our study, we assessed the antidepressant efficacy of pioglitazone on a CMS model, which is commonly used to induce 


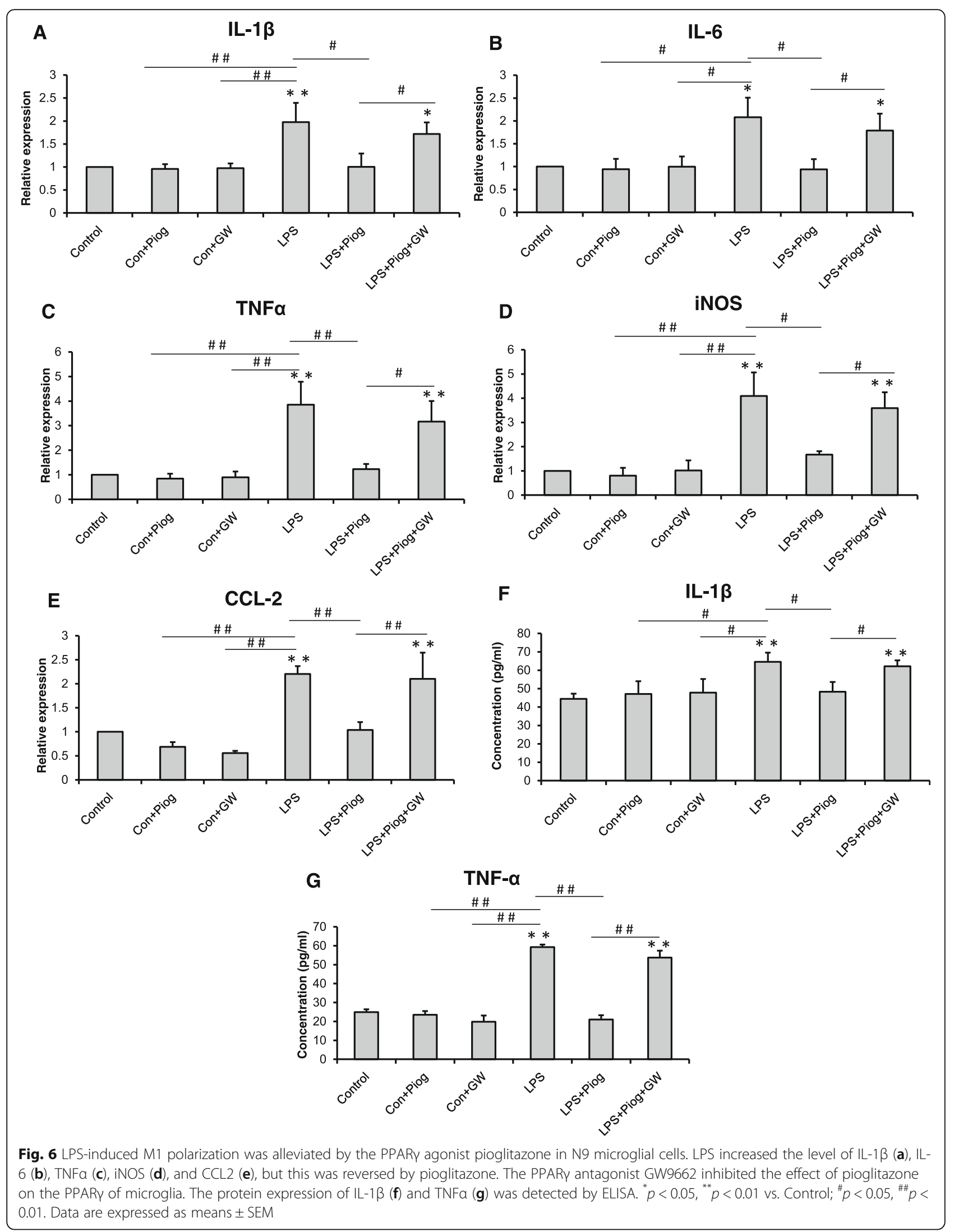




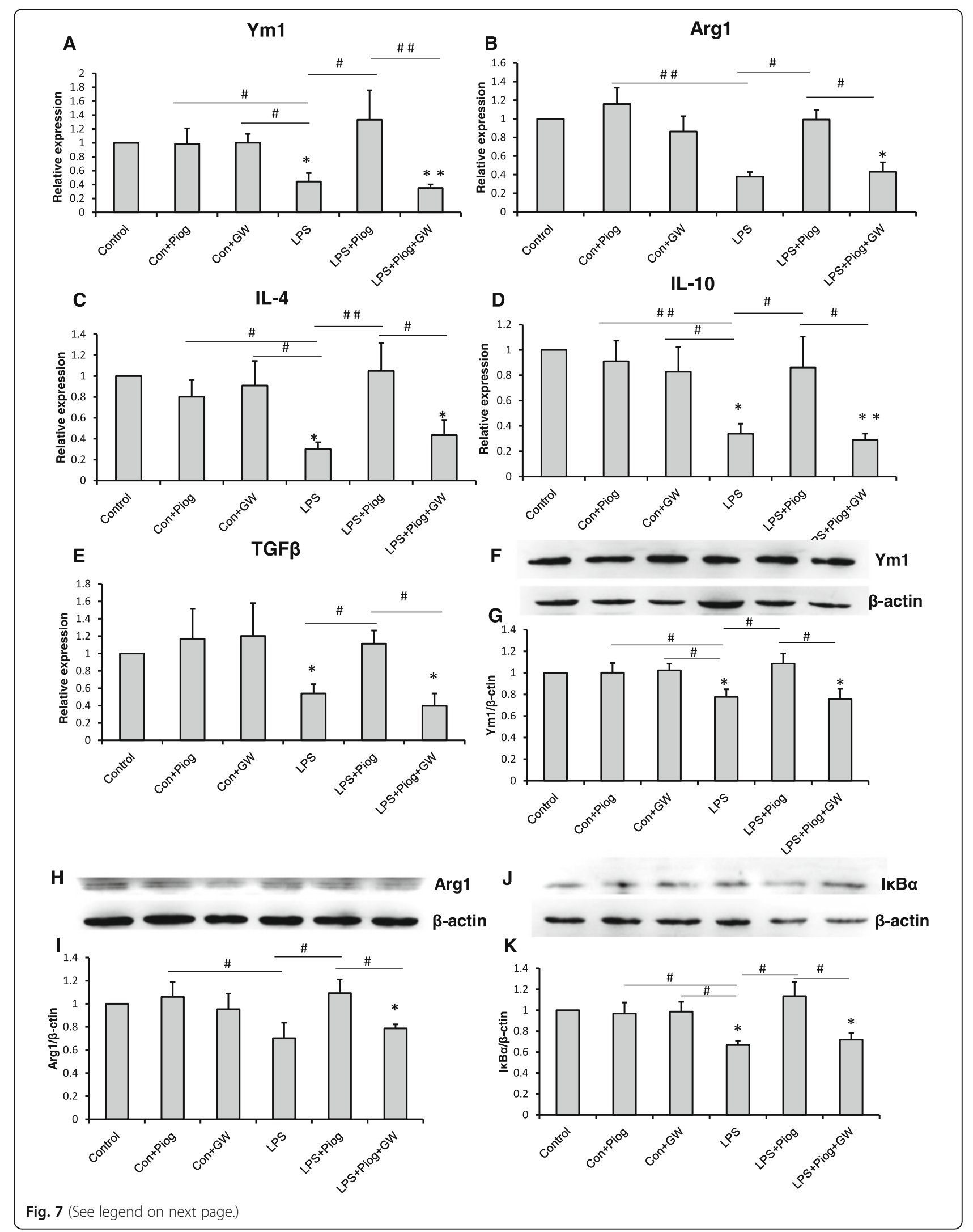


(See figure on previous page.)

Fig. 7 The M2 molecules: Ym1 (a), Arg1 (b), IL-4 (c), IL-10 (d), and TGF 3 (e) decreased with LPS treatment. Pioglitazone increased the expression of the M2 markers. The impact on the LPS+Piog+GW group was similar to that of the LPS microglial cells. The level of Ym1 (f \& $\mathbf{g})$ and Arg1 (h \& i) was also confirmed by western blot. The protein expression of IkBa decreased in LPS-stimulated cells; pioglitazone significantly ameliorated the expression. GW9662 suppressed the rise after pioglitazone-treated LPS in microglia (j \& $\mathbf{k}) .{ }^{*} p<0.05,{ }^{* *} p<0.01$ vs. Control; ${ }^{\#} p<0.05,{ }^{\# \#} p<0.01$. Data are expressed as means \pm SEM

and measure depression (Fig. 1). Because pioglitazone can cross the blood brain barrier, intragastric injection was selected for the CMS mice. Pioglitazone increased the SP in CMS-induced depressant model, which was blocked by the PPAR- $\gamma$ antagonist GW9662. Pioglitazone as well decreased the time of immobility in FST and TST in the CMS-treated mice, indicating that pioglitazone has a therapeutic action in CMS-induced depression-like behaviors. CMS induced a decrease in locomotor activity indicated a depressive state of animals because of a loss of interest for the movement, or for exploring the environment. Pioglitazone increased spontaneous motor activity in the CMS-exposed mice, without effect on locomotor activity in normal mice [38]. Gavage administration of pioglitazone was effective at the 2.5 and $5.0 \mathrm{mg} / \mathrm{kg}$ doses for ameliorating the symptoms of depression, but the $2.5 \mathrm{mg} / \mathrm{kg}$ dosage was more effective. Dosages of 10 and $20 \mathrm{mg} / \mathrm{kg}$ were not efficacious in the CMS mice. As a result, the $2.5 \mathrm{mg} / \mathrm{kg}$ dose was chosen to treat the CMS mice in the subsequent experiments.

PPAR $\gamma$ is a ligand-dependent transcription factor belonging to the nuclear hormone receptor superfamily implicated in adipocyte differentiation, insulin sensitivity, and inflammatory processes $[39,40]$. PPAR $\gamma$ is constitutively expressed in macrophages and CNS-resident microglia, acting as a key regulator of microglial activation [41]. Activation of PPAR signaling has a protective role by reducing neuroinflammation [42], a finding which may present a novel therapeutic approach for diseases, including Alzheimer's disease [20,43], Parkinson's disease [24, 44], stroke [45], schizophrenia, and autism [22]. In light of the anti-inflammatory and neuroprotective activities of the PPAR $\gamma$-dependent signaling pathway, we investigated the antidepressant effects of pioglitazone in a CMS mice model of depression. GW9662, a selective antagonist for PPAR $\gamma$, was administered in this investigation in order to explore the possible role of PPAR $\gamma$ activation on the antidepressant activities of pioglitazone (Fig. 2). After treatment with GW9662, the BW loss was greater than that in the CMS-treated mice. GW9662 significantly inhibited the pioglitazone-induced reduction in the duration of immobility in the FST and TST. GW9662 also counteracted the effect of pioglitazone on PPAR $\gamma$ activation. These results suggest that pioglitazone exerts antidepressant-like effects at least in part due to the activation of the PPAR $\gamma$ pathway.
Microglia play a crucial role in inflammation modulation in the CNS, and microglial dysfunction is believed to result in CNS immune disorders [46, 47]. The role of microglia has long been considered in some neurodegenerative diseases $[48,49]$. Some interesting evidence about this role in depression has also began to emerge in recent years, e.g., microglial activation and the expression of inflammatory mediators have been reported in an olfactory bulbectomised (OB) rat model of depression [50]. According to in vitro research, microglia and their polarization status play an essential role in depression initiation [51]. These data indicated that the immune system was activated in the stressed depression models. This may have been due to the activation of M1 microglia [35]. Here, we showed that the microglial cells had large somas, short thick processes, and the amoeboid morphology typical of activated microglia after CMS initiation (Fig. 3a). This morphology has been explained in our previous experiments [12, 35]. Microglial activated phenotypes were determined by their polarized markers. We confirmed that the M1 markers (IL-1 $\beta$, IL-6, TNF $\alpha$, iNOS, and CCL2) were induced and that the M2 molecules (Ym1, Arg1, IL-4, IL-10, and TGF $\beta$ ) were impaired in depression. Pioglitazone restored the balance of the M1 and M2 microglia in the hippocampus of the CMS mice (Figs. 4 and 5). The hippocampus has been implicated in the inhibition of stress responses [52] and in the regulation of affective states and emotional behavior [53]. Prior studies have shown that stress primed neuroinflammatory processes characterized by microglial activation [14, 15]. Microglial activation plays a vital role in the pathogenesis of many neurodegenerative diseases. Experiments in animal models have provided more direct evidence for a role of activated microglia in depression [50, 54]. In our experiment, we found that pioglitazone can control microglia activation and neuroinflammation in CMS-induced depression. These data indicated that microglia-modulating agents had therapeutic benefits for MDD, thereby defining a new biological activity for pioglitazone by showing that pioglitazone acts in modulating microglial phenotypes in a CMS-induced rodent model of depression.

Inflammatory cytokines play a significant role in depression. In our previous study, an imbalance between the pro- and anti-inflammatory cytokines may be one of the pathogeneses of depression [6]. In this current 
research, a higher expression of IL-1 $\beta$, IL-6, and TNF $\alpha$, and a lower expression of IL-4, IL-10, and TGF- $\beta$ were observed in the hippocampus of CMS-induced mice (Figs. 4 and 5). A relatively large body of evidence has suggested that the PPAR $\gamma$ agonist pioglitazone can regulate the inflammatory response and oxidative stress $[55,56]$. After pioglitazone treatment of the CMS mice, the expression of pro-inflammatory molecules was reduced and the levels of anti-inflammatory cytokines were increased. These results were consistent with recent findings that PPAR $\gamma$ agonists can transition M1 into M2 phenotype as well as enhance the production of anti-inflammatory cytokines such as IL-10 and TGF $\beta$, both of which are pro-neurogenic $[57,58]$. In order to ensure the specific response of activated microglia in stress-induced depression, experiments using LPS treatment of N9 microglial cells were performed. LPS can cause behavioral changes that indicate depression [59]. LPS stimulation can break the balance of microglial activation (M1 vs. M2), but the resulting imbalance in the levels of mRNA and protein can be ameliorated by pioglitazone administration (Fig. 6 and Fig. 7a-i). The results of an in vitro study were consistent with the mice test. Thus, the M1-M2 imbalance should be a focus in studying animal models of depression [50]. NF-kB pathway activation plays an important role in pro-inflammatory gene expression after stimulation $[60,61]$. NF-kB normally exists in the cytoplasm, binding to its inhibitory proteins $(\mathrm{IkB})$ and remaining inactive. Dissociation of $\mathrm{IkB}$ induces activation of NF-kB and facilitates the transcription of inflammatory genes [62]. In our experiment, the protein expression of IkB was reduced after an LPS stimulation of N9 microglial cells. Pioglitazone upregulated the IkB $\alpha$ expression in the LPS-treated N9 cells and GW9662 reversed the inhibitory effects of pioglitazone on NF-kB activity (Fig. 7k). These results indicated that the role of pioglitazone in preventing the NF- $k B$ activation was partially linked to the upregulation of IkB expression. The present findings suggest that the anti-inflammatory effects of pioglitazone are associated with a PPAR $\gamma$-mediated suppression of the NF-kB signaling pathway with consequential inflammatory cytokine expression in microglial cells.

\section{Conclusions}

In summary, the present study demonstrated for the first time that the chronic administration of pioglitazone induced the neuroprotective phenotype of microglia in parallel with the amelioration of depression-like behaviors in CMS-treated C57BL/6 mice. Pioglitazone, a microgliamodulating drug which regulates anti-inflammatory activity, may partially account for the observed antidepressant response. This finding suggests that targeting microglia could pave the way for new depression treatments.

\section{Additional files}

Additional file 1: BW and SP ratio in different weeks of experiment 1. (PDF $77 \mathrm{~kb}$ )

Additional file 2: BW and SP ratio in different weeks of experiment 2. (PDF $77 \mathrm{~kb}$ )

\section{Abbreviations \\ ANOVA: Analysis of variance; Arg1: Arignase1; BW: Body weight; CMS: Chronic mild stress; CNS: Central nervous system; FST: Forced swimming test; GW: GW9662; Iba1: Ionized calcium-binding adaptor protein-1; IkB: Inhibitor of NF-kB; LPS: Lipopolysaccharide; M1: Classical activation; M2: Alternative activation; MAOls: Monoamine oxidase inhibitors; MDD: Major depressive disorder; NF-kB: Nuclear factor kB; OB: Olfactory bulbectomised; Piog: Pioglitazone; PBS: Phosphate-buffered saline; PPARy: Peroxisome proliferator-activated receptor $\gamma$; RT-PCR: Real time-PCR; SP: Sucrose preference; SSRIs: Selective serotonin reuptake inhibitors; TNFa: Tumor necrosis factor-a; TST: Tail suspension test}

\section{Acknowledgements}

We are grateful to Prof. Zujun Yang for his assistance and facilities in immunohistochemistry and to Rhoda E and Edmund F. Perozzi, PhDs, for their extensive review and English language assistance on this paper.

\section{Funding}

This work was supported by the National Natural Science Foundation of China (No. 81571174, 81603503), 863 project (No. 2015AA020505), Key Technologies R \& D Program of Sichuan Province (2015SZ0058-5), and the Open Research Fund of State Key Laboratory Breeding Base of Systematic Research, Development and Utilization of Chinese Medicine Resources (No. 2015003).

\section{Availability of data and materials}

The datasets and materials supporting the conclusions of this article are included within the article and its additional files.

\section{Authors' contributions}

QZ and ZY designed the study and drafted of the manuscript. QZ, XW, and SY performed the experiments. XX and YF managed the literature searches and analyses. QZ and JZ analyzed the data. QZ, CP, and ZY provided interpretation of the data and discussed the manuscript. All authors read and approved the final manuscript.

\section{Competing interests}

The authors declare that they have no competing interests.

Consent for publication

Not applicable

\section{Ethics approval and consent to participate}

All animals care and experimental procedures were approved by the Institutional Animal Care and Use Committee, University of Electronic Science and Technology of China.

Received: 29 January 2016 Accepted: 21 September 2016 Published online: 04 October 2016

\section{References}

1. Centers for Disease Control and Prevention (CDC). Current depression among adults_-United States, 2006 and 2008. MMWR Morb Mortal Wkly Rep. 2010;59:1229-1235.

2. Rush AJ, Trivedi MH, Wisniewski SR, Nierenberg AA, Stewart JW, Warden D, Niederehe G, Thase ME, Lavori PW, Lebowitz BD, et al. Acute and longerterm outcomes in depressed outpatients requiring one or several treatment steps: a STAR*D report. Am J Psychiatry. 2006;163:1905-17.

3. Anderson HD, Pace WD, Libby AM, West DR, Valuck RJ. Rates of 5 common antidepressant side effects among new adult and adolescent cases of depression: a retrospective US claims study. Clin Ther. 2012;34:113-23.

4. Fonseka TM, Mclntyre RS, Soczynska JK, Kennedy SH. Novel investigational drugs targeting IL-6 signaling for the treatment of depression. Expert Opin Investig Drugs. 2015;24:459-75. 
5. Raison CL, Capuron L, Miller AH. Cytokines sing the blues: inflammation and the pathogenesis of depression. Trends Immunol. 2006;27:24-31.

6. You Z, Luo C, Zhang W, Chen Y, He J, Zhao Q, Zuo R, Wu Y. Pro- and antiinflammatory cytokines expression in rat's brain and spleen exposed to chronic mild stress: involvement in depression. Behav Brain Res. 2011;225:135-41.

7. Hanisch UK, Kettenmann H. Microglia: active sensor and versatile effector cells in the normal and pathologic brain. Nat Neurosci. 2007;10:1387-94.

8. Tambuyzer BR, Ponsaerts P, Nouwen EJ. Microglia: gatekeepers of central nervous system immunology. J Leukoc Biol. 2009;85:352-70.

9. Steiner J, Bielau H, Brisch R, Danos P, Ullrich O, Mawrin C, Bernstein HG, Bogerts B. Immunological aspects in the neurobiology of suicide: elevated microglial density in schizophrenia and depression is associated with suicide. J Psychiatr Res. 2008;42:151-7.

10. Michelucci A, Heurtaux T, Grandbarbe L, Morga E, Heuschling P. Characterization of the microglial phenotype under specific proinflammatory and anti-inflammatory conditions: effects of oligomeric and fibrillar amyloid-beta. J Neuroimmunol. 2009;210:3-12.

11. Park J, Min JS, Kim B, Chae UB, Yun JW, Choi MS, Kong IK, Chang KT, Lee DS. Mitochondrial ROS govern the LPS-induced pro-inflammatory response in microglia cells by regulating MAPK and NF-kappaB pathways. Neurosci Lett. 2015:584:191-6.

12. Zhao Q, Xie X, Fan Y, Zhang J, Jiang W, Wu X, Yan S, Chen Y, Peng C, You Z. Phenotypic dysregulation of microglial activation in young offspring rats with maternal sleep deprivation-induced cognitive impairment. Sci Rep. 2015;5:9513.

13. Kobayashi K, Imagama S, Ohgomori T, Hirano K, Uchimura K, Sakamoto K, Hirakawa A, Takeuchi H, Suzumura A, Ishiguro N, Kadomatsu K. Minocycline selectively inhibits M1 polarization of microglia. Cell Death Dis. 2013;7:54.

14. Frank MG, Hershman SA, Weber MD, Watkins LR, Maier SF. Chronic exposure to exogenous glucocorticoids primes microglia to pro-inflammatory stimuli and induces NLRP3 mRNA in the hippocampus. Psychoneuroendocrinology. 2014:40:191-200

15. Han A, Yeo H, Park MJ, Kim SH, Choi HJ, Hong CW, Kwon MS. IL-4/10 prevents stress vulnerability following imipramine discontinuation. J Neuroinflammation. 2015;12:015-0416.

16. Calcia MA, Bonsall DR, Bloomfield PS, Selvaraj S, Barichello T, Howes OD. Stress and neuroinflammation: a systematic review of the effects of stress on microglia and the implications for mental illness. Psychopharmacology (Berl). 2016;233:1637-50.

17. Jafari M, Khodayari B, Felgner J, Bussel II, Rose MR, Mueller LD. Pioglitazone: an anti-diabetic compound with anti-aging properties. Biogerontology. 2007;8:639-51

18. Kemp DE, Ismail-Beigi F, Ganocy SJ, Conroy C, Gao K, Obral S, Fein E, Findling RL, Calabrese JR. Use of insulin sensitizers for the treatment of major depressive disorder: a pilot study of pioglitazone for major depression accompanied by abdominal obesity. J Affect Disord. 2012;136:1164-73.

19. Carta AR, Pisanu A. Modulating microglia activity with PPAR-gamma agonists: a promising therapy for Parkinson's disease? Neurotox Res. 2013;23:112-23.

20. Mandrekar-Colucci S, Karlo JC, Landreth GE. Mechanisms underlying the rapid peroxisome proliferator-activated receptor-gamma-mediated amyloid clearance and reversal of cognitive deficits in a murine model of Alzheimer's disease. J Neurosci. 2012;32:10117-28.

21. Spiegelman BM. PPAR-gamma: adipogenic regulator and thiazolidinedione receptor. Diabetes. 1998;47:507-14.

22. Boris M, Kaiser CC, Goldblatt A, Elice MW, Edelson SM, Adams JB, Feinstein DL. Effect of pioglitazone treatment on behavioral symptoms in autistic children. J Neuroinflammation. 2007:4:3.

23. Sato T, Hanyu H, Hirao K, Kanetaka H, Sakurai H, Iwamoto T. Efficacy of PPAR-gamma agonist pioglitazone in mild Alzheimer disease. Neurobiol Aging. 2011;32:1626-33.

24. NINDS Exploratory Trials in Parkinson Disease (NET-PD) FS-ZONE Investigators. Pioglitazone in early Parkinson's disease: a phase 2, multicentre, double-blind, randomised trial. Lancet Neurol. 2015;14:795-803.

25. Kaiser CC, Shukla DK, Stebbins GT, Skias DD, Jeffery DR, Stefoski D, Katsamakis $G$, Feinstein DL. A pilot test of pioglitazone as an add-on in patients with relapsing remitting multiple sclerosis. J Neuroimmunol. 2009;211:124-30.

26. Ji S, Kronenberg G, Balkaya M, Farber K, Gertz K, Kettenmann H, Endres M. Acute neuroprotection by pioglitazone after mild brain ischemia without effect on long-term outcome. Exp Neurol. 2009;216:321-8.

27. Lin KW, Wroolie TE, Robakis T, Rasgon NL. Adjuvant pioglitazone for unremitted depression: clinical correlates of treatment response. Psychiatry Res. 2015;230:846-52.
28. Salehi-Sadaghiani M, Javadi-Paydar M, Gharedaghi MH, Zandieh A Heydarpour P, Yousefzadeh-Fard Y, Dehpour AR. NMDA receptor involvement in antidepressant-like effect of pioglitazone in the forced swimming test in mice. Psychopharmacology (Berl). 2012;223:345-55.

29. Sadaghiani MS, Javadi-Paydar M, Gharedaghi MH, Fard YY, Dehpour AR. Antidepressant-like effect of pioglitazone in the forced swimming test in mice: the role of PPAR-gamma receptor and nitric oxide pathway. Behav Brain Res. 2011;224:336-43.

30. Kemp DE, Schinagle M, Gao K, Conroy C, Ganocy SJ, Ismail-Beigi F, Calabrese JR. PPAR-gamma agonism as a modulator of mood: proof-ofconcept for pioglitazone in bipolar depression. CNS Drugs. 2014;28:571-81.

31. Gamaro GD, Manoli LP, Torres IL, Silveira R, Dalmaz C. Effects of chronic variate stress on feeding behavior and on monoamine levels in different rat brain structures. Neurochem Int. 2003:42:107-14.

32. Micale V, Kucerova J, Sulcova A. Leading compounds for the validation of animal models of psychopathology. Cell Tissue Res. 2013;354:309-30.

33. Cryan JF, Mombereau C, Vassout A. The tail suspension test as a model for assessing antidepressant activity: review of pharmacological and genetic studies in mice. Neurosci Biobehav Rev. 2005;29:571-625.

34. Porsolt RD, Le Pichon M, Jalfre M. Depression: a new animal model sensitive to antidepressant treatments. Nature. 1977;266:730-2.

35. Zhao Q, Peng C, Wu X, Chen Y, Wang C, You Z. Maternal sleep deprivation inhibits hippocampal neurogenesis associated with inflammatory response in young offspring rats. Neurobiol Dis. 2014;68:57-65.

36. Sepanjnia K, Modabbernia A, Ashrafi M, Modabbernia MJ, Akhondzadeh S. Pioglitazone adjunctive therapy for moderate-to-severe major depressive disorder: randomized double-blind placebo-controlled trial. Neuropsychopharmacology. 2012;37:2093-100.

37. Kashani L, Omidvar T, Farazmand B, Modabbernia A, Ramzanzadeh F, Tehraninejad ES, Ashrafi M, Tabrizi M, Akhondzadeh S. Does pioglitazone improve depression through insulin-sensitization? Results of a randomized double-blind metformin-controlled trial in patients with polycystic ovarian syndrome and comorbid depression. Psychoneuroendocrinology. 2013;38: $767-76$.

38. Sanchis-Gomar F, Pareja-Galeano H, Martinez-Bello VE. PPARgamma agonist pioglitazone does not enhance performance in mice. Drug Test Anal. 2014; 6:922-9.

39. Li ZY, Song J, Zheng SL, Fan MB, Guan YF, Qu Y, Xu J, Wang P, Miao CY. Adipocyte Metrnl antagonizes insulin resistance through PPARgamma signaling. Diabetes. 2015;64:4011-22.

40. Mclntyre RS, Soczynska JK, Woldeyohannes HO, Lewis GF, Leiter LA, MacQueen GM, Miranda A, Fulgosi D, Konarski JZ, Kennedy SH. Thiazolidinediones: novel treatments for cognitive deficits in mood disorders? Expert Opin Pharmacother. 2007;8:1615-28.

41. Carta AR, Pisanu A, Carboni E. Do PPAR-gamma agonists have a future in Parkinson's disease therapy? Parkinsons Dis. 2011;689181:29.

42. Pan J, Jin JL, Ge HM, Yin $\mathrm{KL}$, Chen $X$, Han LJ, Chen Y, Qian L, Li XX, XU $Y$. Malibatol A regulates microglia M1/M2 polarization in experimental stroke in a PPARgamma-dependent manner. J Neuroinflammation. 2015; 12:015-0270.

43. Skerrett R, Pellegrino MP, Casali BT, Taraboanta L, Landreth GE. Combined liver $X$ receptor/peroxisome proliferator-activated receptor gamma agonist treatment reduces amyloid beta levels and improves behavior in amyloid precursor protein/presenilin 1 mice. J Biol Chem. 2015;290:21591-602.

44. Pisanu A, Lecca D, Mulas G, Wardas J, Simbula G, Spiga S, Carta AR. Dynamic changes in pro- and anti-inflammatory cytokines in microglia after PPARgamma agonist neuroprotective treatment in the MPTPp mouse model of progressive Parkinson's disease. Neurobiol Dis. 2014;71:280-91.

45. Cuartero MI, Ballesteros I, Moraga A, Nombela F, Vivancos J, Hamilton JA, Corbi AL, Lizasoain I, Moro MA. N2 neutrophils, novel players in brain inflammation after stroke: modulation by the PPARgamma agonist rosiglitazone. Stroke. 2013;44:3498-508.

46. Saijo K, Glass CK. Microglial cell origin and phenotypes in health and disease. Nat Rev Immunol. 2011;11:775-87.

47. David S, Kroner A. Repertoire of microglial and macrophage responses after spinal cord injury. Nat Rev Neurosci. 2011;12:388-99.

48. Jimenez S, Baglietto-Vargas D, Caballero C, Moreno-Gonzalez I, Torres M, Sanchez-Varo R, Ruano D, Vizuete M, Gutierrez A, Vitorica J. Inflammatory response in the hippocampus of PS1M146L/APP751SL mouse model of Alzheimer's disease: age-dependent switch in the microglial phenotype from alternative to classic. J Neurosci. 2008;28:11650-61. 
49. Varnum MM, Ikezu T. The classification of microglial activation phenotypes on neurodegeneration and regeneration in Alzheimer's disease brain. Arch Immunol Ther Exp. 2012;60:251-66.

50. Burke NN, Kerr DM, Moriarty O, Finn DP, Roche M. Minocycline modulates neuropathic pain behaviour and cortical M1-M2 microglial gene expression in a rat model of depression. Brain Behav Immun. 2014;42:147-56.

51. Pusic KM, Pusic AD, Kemme J, Kraig RP. Spreading depression requires microglia and is decreased by their M2a polarization from environmental enrichment. Glia. 2014;62:1176-94.

52. Lopez JF, Akil H, Watson SJ. Neural circuits mediating stress. Biol Psychiatry. 1999:46:1461-71.

53. McEwen BS, Magarinos AM. Stress and hippocampal plasticity: implications for the pathophysiology of affective disorders. Hum Psychopharmacol. 2001; 16:S7-19.

54. Henry CJ, Huang Y, Wynne A, Hanke M, Himler J, Bailey MT, Sheridan JF, Godbout JP. Minocycline attenuates lipopolysaccharide (LPS)-induced neuroinflammation, sickness behavior, and anhedonia. J Neuroinflammation. 2008:5:1742-2094

55. De Nuccio C, Bernardo A, Cruciani C, De Simone R, Visentin S, Minghetti L. Peroxisome proliferator activated receptor-gamma agonists protect oligodendrocyte progenitors against tumor necrosis factor-alpha-induced damage: effects on mitochondrial functions and differentiation. Exp Neurol. 2015;271:506-14.

56. El-Gowilly SM, Helmy MM, El-Gowelli HM. Pioglitazone ameliorates methotrexate-induced renal endothelial dysfunction via amending detrimental changes in some antioxidant parameters, systemic cytokines and Fas production. Vascul Pharmacol. 2015;74:139-50.

57. Yu Z, Sun D, Feng J, Tan W, Fang X, Zhao M, Zhao X, Pu Y, Huang A, Xiang $Z$, et al. MSX3 switches microglia polarization and protects from inflammation-induced demyelination. J Neurosci. 2015;35:6350-65.

58. Papadopoulos P, Rosa-Neto P, Rochford J, Hamel E. Pioglitazone improves reversal learning and exerts mixed cerebrovascular effects in a mouse model of Alzheimer's disease with combined amyloid-beta and cerebrovascular pathology. PLoS One. 2013;8:e68612.

59. Adzic M, Djordjevic J, Mitic M, Brkic Z, Lukic I, Radojcic M. The contribution of hypothalamic neuroendocrine, neuroplastic and neuroinflammatory processes to lipopolysaccharide-induced depressive-like behaviour in female and male rats: involvement of glucocorticoid receptor and C/EBP-beta. Behav Brain Res. 2015;291:130-9.

60. Qin ZH, Tao LY, Chen X. Dual roles of NF-kappaB in cell survival and implications of NF-kappaB inhibitors in neuroprotective therapy. Acta Pharmacol Sin. 2007;28:1859-72.

61. Lawrence T. The nuclear factor NF-kappaB pathway in inflammation. Cold Spring Harb Perspect Biol. 2009;1:7.

62. Baeuerle PA, Baltimore D. NF-kappa B: ten years after. Cell. 1996;87(1):13-20.

\section{Submit your next manuscript to BioMed Central and we will help you at every step:}

- We accept pre-submission inquiries

- Our selector tool helps you to find the most relevant journal

- We provide round the clock customer support

- Convenient online submission

- Thorough peer review

- Inclusion in PubMed and all major indexing services

- Maximum visibility for your research

Submit your manuscript at www.biomedcentral.com/submit

) Biomed Central 